\title{
An assessment of multimodal imaging of subsurface text in mummy cartonnage using surrogate papyrus phantoms
}

\author{
Adam Gibson ${ }^{1 *} \mathbb{D}$, Kathryn E. Piquette ${ }^{2}$, Uwe Bergmann ${ }^{3}$, William Christens-Barry ${ }^{4}$, Graham Davis ${ }^{5}$, \\ Marco Endrizzi ${ }^{1}$, Shuting Fan ${ }^{6}$, Sina Farsiu ${ }^{7}$, Anthony Fitzgerald ${ }^{6}$, Jennifer Griffiths ${ }^{8}$, Cerys Jones ${ }^{1}$, Guorong Li ${ }^{7}$,

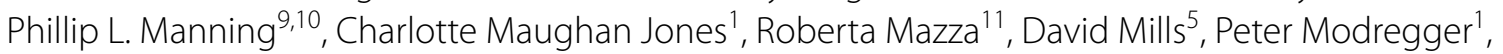 \\ Peter R. T. Munro ${ }^{1}$, Alessandro Olivo ${ }^{1}$, Alice Stevenson ${ }^{12}$, Bindia Venugopal ${ }^{1}$, Vincent Wallace ${ }^{6}$, \\ Roy A. Wogelius ${ }^{9,10}$, Michael B. Toth ${ }^{13}$ and Melissa Terras ${ }^{14}$
}

\begin{abstract}
Ancient Egyptian mummies were often covered with an outer casing, panels and masks made from cartonnage: a lightweight material made from linen, plaster, and recycled papyrus held together with adhesive. Egyptologists, papyrologists, and historians aim to recover and read extant text on the papyrus contained within cartonnage layers, but some methods, such as dissolving mummy casings, are destructive. The use of an advanced range of different imaging modalities was investigated to test the feasibility of non-destructive approaches applied to multi-layered papyrus found in ancient Egyptian mummy cartonnage. Eight different techniques were compared by imaging four synthetic phantoms designed to provide robust, well-understood, yet relevant sample standards using modern papyrus and replica inks. The techniques include optical (multispectral imaging with reflection and transillumination, and optical coherence tomography), X-ray (X-ray fluorescence imaging, X-ray fluorescence spectroscopy, $X$-ray micro computed tomography and phase contrast $X$-ray) and terahertz-based approaches. Optical imaging techniques were able to detect inks on all four phantoms, but were unable to significantly penetrate papyrus. X-ray-based techniques were sensitive to iron-based inks with excellent penetration but were not able to detect carbon-based inks. However, using terahertz imaging, it was possible to detect carbon-based inks with good penetration but with less sensitivity to ironbased inks. The phantoms allowed reliable and repeatable tests to be made at multiple sites on three continents. The tests demonstrated that each imaging modality needs to be optimised for this particular application: it is, in general, not sufficient to repurpose an existing device without modification. Furthermore, it is likely that no single imaging technique will to be able to robustly detect and enable the reading of text within ancient Egyptian mummy cartonnage. However, by carefully selecting, optimising and combining techniques, text contained within these fragile and rare artefacts may eventually be open to non-destructive imaging, identification, and interpretation.
\end{abstract}

Keywords: Mummy cartonnage, Papyrus, Phantom, Surrogate, Heritage imaging

\section{Introduction}

Egyptian mummies are perhaps the most iconic objects from the ancient world. The tradition of mummification persisted for thousands of years, using processes and

\footnotetext{
${ }^{*}$ Correspondence: adam.gibson@ucl.ac.uk

${ }^{1}$ Department of Medical Physics and Biomedical Engineering, UCL, London WC1E 6BT, UK

Full list of author information is available at the end of the article
}

materials which changed geographically and through time. Much is now known of both the mummification process and the mummies themselves, partly due to the application of modern imaging techniques, often derived from medical imaging [1]. Our interest here, however, is in the cartonnage cases, panels and masks used to cover the mummified and wrapped body. Cartonnage is a composite material made up of layers of various materials, 
such as linen and papyrus which were covered with plaster that was often brightly painted [2]. By the Ptolemaic Period (323-30BCE), it was becoming common to make cartonnage from old inscribed papyrus sheet and rolls that were frequently cut and moulded to support the painted plaster. The manufacturing process used sections of papyrus in such a way that they are relatively well preserved and now form a rich source of manuscripts from this period.

The discovery that mummy cartonnage could contain writing dates back to the earliest years of papyrology and Egyptology. The first person to have retrieved papyri from mummy cartonnage seems to have been the French archaeologist Jean Antoine Letronne c1825CE who was disappointed by their poor state of preservation and administrative contents [3]. In the early twentieth century, British papyrologists Grenfell and Hunt also realized that mummy cartonnage could contain recycled material and discovered, by chance, that discarded papyri had been used as part of the wrappings of crocodile mummies [4].

Accessing the textual content of these recycled papyrus sheets and rolls is challenging and, although methods have improved in recent years, there is a consensus that all have been invasive to some extent [5]. Indeed, a number of controversial techniques have been used. Private owners of cartonnage of uncertain provenance have dissolved mummy masks and other cartonnage in water and soap to access papyri. The circulation of online videos, where these achievements were publicised without any respect for the many issues connected with this practice, has been condemned by the scientific community [6-10]. This phenomenon raises many concerns not only for the destructive methods employed, but also for the message it conveys to private owners and dealers, who may be attracted to destroy cultural heritage objects for their own aims. The dismounting of cartonnage causes the loss of material cultural evidence, even when performed through appropriate techniques and fully documented.

Our contribution to this debate is to investigate the potential for modern non-destructive imaging techniques to identify, characterise and potentially enable the writing on papyrus which is beneath the surface of the object and invisible to the naked eye to be read. This research will inform the debate, publicise the damage caused by destructive techniques, assist conservators, and ultimately avoid the need for destructive analysis of these objects.

To image writing in cartonnage successfully, an imaging technique needs to penetrate multiple layers of papyrus which may have been secured using adhesives, covered with plaster and contain air gaps. The technique must then detect paints in the form of dyes (which dissolve in water, are usually organic and adhere to the substrate) and pigments (which retain their particulate form and may be insoluble in water, but require a binder for surface adhesion), both of which may change characteristics over time [11]. Imaging techniques were selected that were expected to give contrast to either organic or inorganic pigments underneath layers of papyrus. Eight different imaging approaches were used, taken from optical imaging, X-ray imaging and terahertz imaging.

The assessment of this wide range of imaging modalities presented here begins by using surrogate papyrus "phantoms" which provide a test platform that is more controlled and well characterised than original cartonnage. The use of well controlled test samples to characterise a system is standard practice in chemistry and the analytical sciences, and the use of digital and physical test phantoms for image characterisation is widespread in medical imaging $[12,13]$. While both have been used in heritage science $[14,15]$, the method is not widespread, perhaps because of the approach that all heritage objects should be seen as individual and unique. However, the same is true of patients in medical imaging. The purpose of a phantom is not to reproduce all aspects of the object being examined, but to provide a simplified, reproducible and well understood object of low value whose characteristics are known and so can be used to compare and validate results objectively and safely. In this case, a simplified test object also allows the fundamental characteristics which are common to all cartonnage of interest-papyrus and ink-to be extracted from the complexities of adhesives, plaster, paint, and changes which occur over time, thereby allowing contributions from different variables to be assessed individually. Moreover, modern phantoms can be imaged and handled repeatedly without risk of damage, and can be shipped internationally without needing to deal with import restrictions. Such restrictions on shipping ancient artefacts, especially those closely associated with human remains, are complex, vary between jurisdictions and change over time. These advantages of using phantoms, it transpired, were critical to the success of the project.

\section{Methods}

\section{Design and construction of test phantoms}

The phantoms were designed to isolate the challenges of imaging inks within papyrus by reproducing important features but avoiding the additional complexities of plaster, overlapping layers of text, damage, and other confounding factors. This allowed the characteristics of different imaging techniques to be determined under ideal conditions. Although these ideal conditions may never arise in historical artefacts, phantoms can inform 


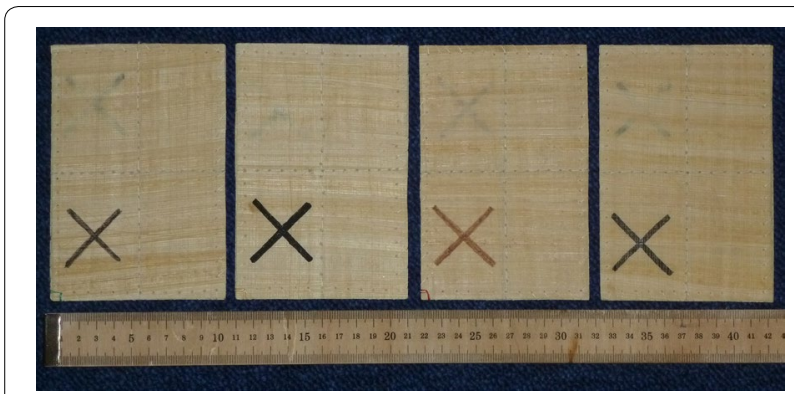

Fig. 1 Photographs of the four phantoms. From left, crosses in: iron gall ink; carbon ink; red iron oxide and India ink. A ruler is shown for scale

the interpretation and selection of different imaging modalities.

Four phantoms were constructed (Fig. 1), each made from four $10 \mathrm{~cm} \times 15 \mathrm{~cm}$ sheets of modern papyrus. The sheets were handmade using traditional methods without modern binders or adhesives and had two layers of papyrus pith per sheet ("genuine papyrus" from greatart. co.uk). Each sheet was marked with a cross on one of four quadrants: the four crosses being under zero, one, two and three sheets of papyrus, respectively. A different ink was used to prepare each phantom. Three were selected to be representative of those used historically (carbon ink $^{1}$ and red iron oxide ${ }^{2}$ ink being most common, and to a lesser extent, iron gall ink ${ }^{3}$ ) and one a modern carbonbased India ink (Winsor and Newton, UK) to provide a well-characterised, reproducible control sample. The inks were applied using a modern ink pen, as a traditional reed pen was found to give lines of inconsistent thickness. The ink mainly lay on the surface of each sheet, with minimal noticeable penetration into the papyrus.

To avoid confounding factors arising from the use of adhesive, the papyrus sheets were not glued together but stitched into a flat composite. A single sheet was measured to be $0.33 \pm 0.04 \mathrm{~mm}$ thick, and the composite phantoms all had similar thicknesses of $1.1 \pm 0.1$, $1.2 \pm 0.1,1.3 \pm 0.1$ and $1.2 \pm 0.1 \mathrm{~mm}$ for the phantoms with iron gall, carbon, red iron oxide and Indian ink, respectively. This suggests that, even though the

\footnotetext{
${ }^{1}$ Carbon ink was made by grinding soot into a fine powder, mixing to a paste with deionised water and then mixing into the binder.

2 Red iron oxide ink was made by grinding red earth (Aswan, Egypt) with a pestle and mortar, making the resulting powder into a paste with deionised water and then mixing in a binder of one part powdered gum Arabic (Kurdufan, Central Sudan) to two parts water.

${ }^{3}$ Iron gall ink was made by soaking five oak galls overnight, then crushing them, boiling in deionised water and straining. Iron sulphate II and a dash of white wine were added. A binder of one part powdered gum Arabic (Kurdufan, Central Sudan) to two parts water was used.
}

phantoms were not glued, any air gap existing between the sheets was very small.

The phantoms were stored in resin frames to protect them and keep them flat, but were removed from the frames before being imaged using a range of modalities, as described below.

\section{Multispectral imaging}

Multispectral imaging is an extension of standard digital photography whereby an object is illuminated sequentially under different wavelengths from ultraviolet to near infrared and photographed [15-17]. Blue and ultraviolet light may excite fluorescence of inks or substrates, so filters are used to exclude the illumination light, enhancing the fluorescent signal. The multispectral imaging system used at UCL (R B Toth Associates, USA) is based around a PhaseOne IQ260 60 megapixel, 16 bit achromatic digital camera back and iXR body, and a $120 \mathrm{~mm}$ Schneider $\mathrm{f} / 4$ achromatic macro lens. Two lighting panels (Equipoise Imaging LLC, USA) contain LEDs which emit light at 12 wavelengths from 370 to $940 \mathrm{~nm}$, and long pass filters can be used to image fluorescence by excluding the illuminating light from capture by the camera. Light in this wavelength range is widely used in heritage applications as it can be detected with a silicon sensor, allowing high resolution imaging with consumer devices. The system is controlled using Spectral XV software (Equipoise Imaging LLC, USA).

Phantoms were imaged using 12 wavelengths without filters, and four with filters applied. "Flat field" images were also acquired of a sheet of uniform white photographic print paper to characterise the uniformity of illumination and distortions within the camera such as vignetting. All images were divided by the flat fields prior to subsequent analysis. Analysis involved examination of an image at a single wavelength, taking the ratio of images at different wavelengths, and more sophisticated methods like principal component analysis (PCA: a linear transformation of the images which provides a new set of images which often emphasise differences between the original images) [18].

\section{Transillumination}

Transillumination is a specific type of multispectral imaging. In the previous application of multispectral imaging described above, the illumination and detection occur on the same side of the object, in what may be referred to as a "reflection" mode. The effective depth of penetration is therefore limited because even if light does penetrate deep into the object, once it returns to the surface to be detected, it tends to be overwhelmed by the accumulated reflections from all shallower regions traversed by the light. 
Transillumination or backlighting helps to mitigate against this by illuminating from the reverse of the object and detecting only light which has passed through it. This approach is commonly used in conjunction with multispectral imaging when analysing documents, and has had particular success when examining watermarks [19]. A bespoke illuminator containing an array of 28 white LEDs (LUMEX SLX-LX5093UWC/C, Farnell, UK) was used with the PhaseOne camera system described above. Filters were used to allow some limited assessment of wavelength dependence.

\section{Optical coherence tomography}

Optical coherence tomography (OCT) is a photonic imaging technique predominantly used in ophthalmology [20]. It compares near infrared light that has scattered back from different depths in a sample to a reference signal in an interferometric approach which can provide micrometre resolution to a depth of approximately $1-2 \mathrm{~mm}$ in tissue. It is becoming increasingly common in heritage applications [21], particularly when looking for underdrawings $[22,23]$.

Two spectral domain OCT systems were used in this work: an Envisu R2200 system (Bioptigen, USA) at Duke University Eye Centre with a central wavelength of 840 $\mathrm{nm}$ and a Telestro system (Thorlabs, USA) at UCL, centred at $1300 \mathrm{~nm}$.

\section{X-ray micro computed tomography}

$\mathrm{X}$-ray micro computed tomography (XMT) provides high resolution images of the spatial distribution of $\mathrm{X}$-ray attenuation within a medium. The phantoms were imaged using a high-contrast time-delay integration XMT system developed in-house and based around a chassis and source supplied by X-Tek (now Nikon Metrology, UK) at Queen Mary University of London. An $\mathrm{X}$-ray tube potential of $40 \mathrm{kVp}$ was used with a tungsten target and a $0.5 \mathrm{~mm}$ aluminium filter with a $5 \mu \mathrm{m}$ focal spot size. The detector is a 16 megapixel CCD camera (Spectral Instruments, USA) coupled with fibre optics to a CsI scintillator (Applied Scintillation Technologies, UK). Previously, the system has been used to image heritage objects such as burnt parchment manuscript rolls [24] and historical film footage [25].

The phantoms were separated by plastazote LD- 45 foam sheets and gently curved in a plastic holder. This approach allowed all four phantoms to be imaged simultaneously. In this set-up, the source and detector remain fixed and the sample rotates.

\section{X-ray fluorescence spectroscopy and imaging}

When X-rays interact with a medium, X-rays may be emitted at a lower energy characteristic of the elemental composition of the object: a process known as X-ray fluorescence (XRF). This approach has commonly been used for analysing the composition of heritage objects [26-28]. Two different systems for measuring X-ray fluorescence were used: (1) synchrotron rapid scanning (SRS) XRF imaging using a monochromatic incident X-ray energy of $13.5 \mathrm{keV}$ at the Stanford Synchrotron Radiation Lightsource (SSRL, Stanford University, USA); and (2) handheld portable pXRF using an Olympus Delta Premium $\mathrm{XRF}$ analyser which emits at energies up to $40 \mathrm{keV}$. The former was operated in a high-resolution scanning mode and the latter gave spot measurements.

The pXRF system was held in a clamp stand over the phantom which sat on a $30 \mathrm{~cm}$ box of expanded polystyrene. This ensured that the system was sufficiently far from any background material that the signal could be assumed to result from the papyrus phantom itself.

\section{X-ray phase contrast imaging}

Conventional X-ray techniques are sensitive to the $\mathrm{X}$-ray attenuation of a medium, but materials such as papyrus have low attenuation, so contrast is low. Phase contrast $\mathrm{X}$-ray generates images of the refraction of $\mathrm{X}$-rays as they pass through a medium and therefore offers an alternative contrast mechanism. These methods usually require monochromatic, collimated beams from synchrotrons and have been used for cultural heritage, most famously for imaging the Herculaneum papyri scrolls $[29,30]$. However, a laboratory-based edge-illumination X-ray phase contrast system at UCL operating at $25 \mathrm{~mA}$ current and $40 \mathrm{kVp}$ voltage was used in this application [31]. Although a lab-based system is more suitable for delicate heritage artefacts, it should be noted that this system had been built for research into medical imaging applications and improved performance would be expected from a system optimised specifically for imaging cartonnage. The field of view is $\sim 2 \mathrm{~cm} \times 5 \mathrm{~cm}$ and multiple images, showing parameters such as X-ray absorption, refraction and scatter width are obtained $[32,33]$.

\section{Terahertz imaging and spectroscopy}

Terahertz frequencies $(0.1-10 \mathrm{THz}$, or equivalently, wavelengths of $0.03-3 \mathrm{~mm}$ ) lie between infrared and microwave radiation. The photon energy at $1 \mathrm{THz}$ is very low, $4.14 \mathrm{meV}$, meaning that terahertz radiation is nonionising. This radiation mainly interacts with the intermolecular chemical bonds, so provides image contrast depending on the chemical composition of the materials present. This technique is beginning to be applied in heritage science $[34,35]$. The phantoms were imaged with a TeraPulse4000 system (Teraview Ltd, Cambridge, UK) at the University of Western Australia. The pulses of $\mathrm{THz}$ are generated in this system by the excitation of a low 
temperature grown GaAs wafer with a gold deposited bow-tie antenna with a $780 \mathrm{~nm}$ near infrared laser with a pulse width $\sim 100 \mathrm{fs}$. The image is formed by raster scanning the beam across the sample in $x$ and $y$ directions. This is a time-domain imaging system, in which each pixel contains the reflected $\mathrm{THz}$ pulse signal (amplitude and phase). Thus a three dimensional dataset $(x, y, t)$ is obtained where the third dimension is time which, if the structure and refractive index of the sample are known, can be converted into depth. A reference measurement is acquired from an optically flat metallic mirror, and is deconvolved from the sample pulse prior to further analysis of the signal.

\section{Results}

\section{Performance of test phantoms}

The test phantoms, mounted either in resin frames or within the pages of a book for protection during transport, were successfully imaged using multiple modalities in laboratories across three continents. Despite repeated handling, transport and imaging sessions, images of the phantoms taken at UCL at the start and end of the project (Nov 2015-Mar 2017) were indistinguishable by eye from each other, suggesting that the properties of the phantoms had not changed substantially during the 18 months or so of the study. In more detailed analysis, the mean difference in the measured intensity across all pixels in images acquired on the same day (in an area selected to avoid edges, thread or ink) was $\sim 0.3 \%$. This was taken to be an estimate of the test-retest reproducibility of the system. Multispectral images of the four phantoms were acquired at the beginning and end of the project, 18 months apart. They were aligned by registration using the Mattes mutual information algorithm [Matlab 2016a (The Mathworks, USA)] and had a mean difference (after registration, and after the lights had been repositioned), of 4.2\% (iron gall), 1.1\% (carbon ink),
$1.0 \%$ (red iron oxide ink) and $0.8 \%$ (India ink). Differences of $\sim 1 \%$ were assumed to be due to errors in registration and different lighting conditions. The higher difference occurred to the phantom with crosses in iron gall ink and suggests that there may have been some damage to that phantom during transit or handling.

\section{Multispectral imaging}

For all phantoms, the greatest penetration was seen with the longest wavelength, $940 \mathrm{~nm}$ (shown in Fig. 2). Images processed with PCA (Fig. 3) were unable to demonstrate improved penetration. Similarly, other approaches such as image subtraction were unsuccessful.

Unfortunately, measurements of contrast or signal-tonoise ratio were unsatisfactory, as the eye-brain system is guided by the shape of the cross. On a purely quantitative measurement of signal-to-noise ratio, even the second cross, which is clear on visual examination, has a signal which is less than two standard deviations above variations in the background.

Multispectral imaging offers excellent spatial resolution and some spectral information for inks on the surface or under one layer of papyrus, but the information content soon diminishes with depth.

\section{Transillumination}

Images obtained with white light transillumination are shown in Fig. 4. Here, crosses on all four layers are clearly visible, although those in deeper layers are somewhat less clear than those in the top layers. No appreciable difference was observed when filters were used. Transillumination images displayed a large dynamic range (due to absorption by the papyrus, the majority of the images were very dark although the transilluminating light gave very strong responses from pinholes in the phantoms). The images were therefore enhanced using the Auto Equalise function of Gimp 2.8 (http://www.gimp.
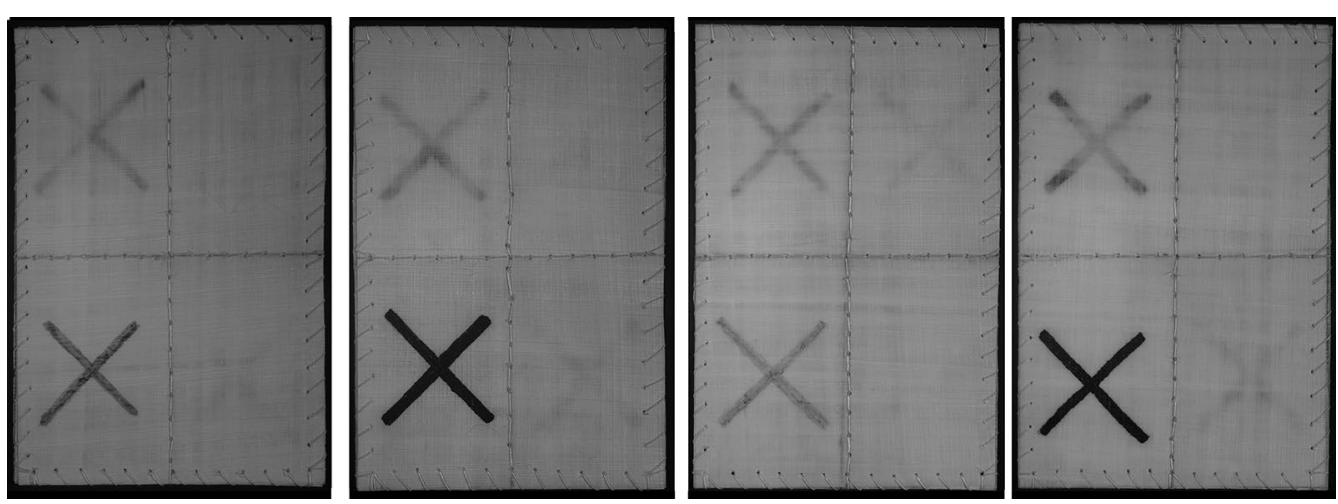

Fig. 2 Multispectral images of all four phantoms (with from left, crosses in: iron gall ink; carbon ink; red iron oxide and India ink) at $940 \mathrm{~nm}$, normalized, showing penetration down to the third layer 

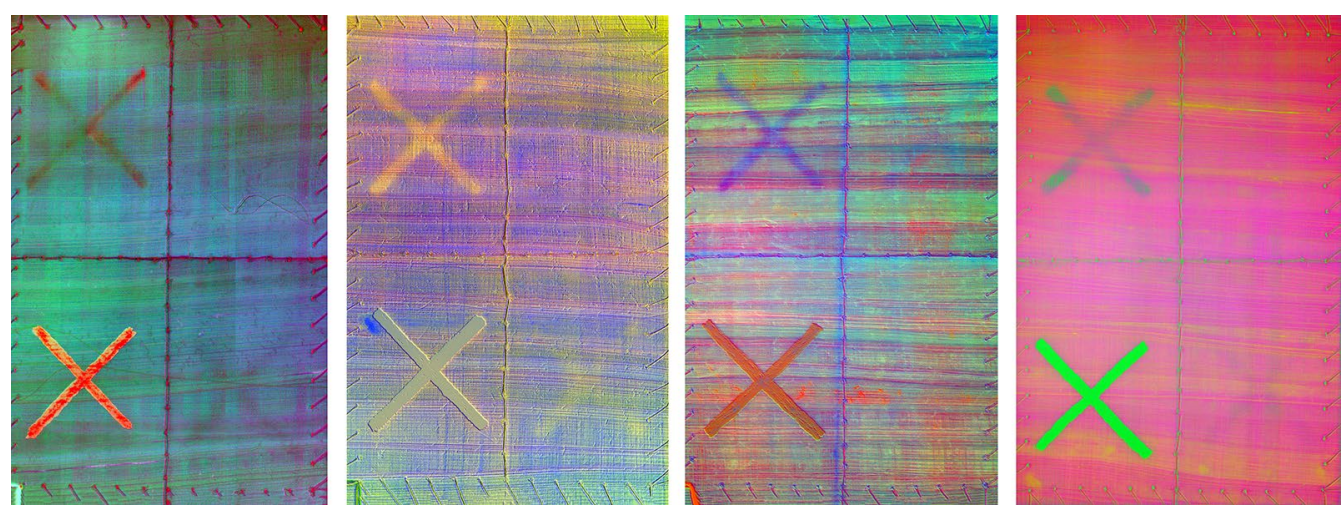

Fig. 3 Pseudocolour renderings of (from left) phantoms with crosses in: iron gall ink; carbon ink; red iron oxide and India ink following principal component analysis. The analysis was intended to maximise contrast of the deepest crosses
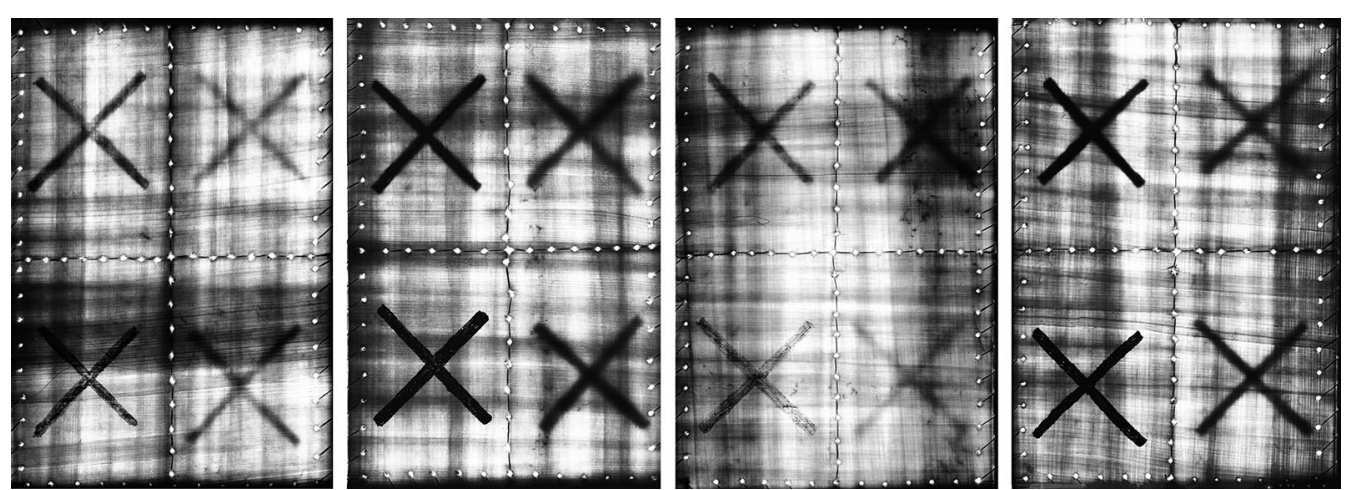

Fig. 4 Images obtained of all four phantoms (from left, crosses in: iron gall ink; carbon ink; red iron oxide and India ink) under transillumination with white light

org), and show the structure of the papyrus as well as the crosses.

This transillumination system was not optimised for this application, but gave substantially improved penetration compared to multispectral imaging. Future developments include a bespoke system with adjustable wavelengths which is anticipated to offer similar penetration but enhanced spectral information.

\section{Optical coherence tomography}

OCT images were initially obtained of all four phantoms using a clinical system at Duke University Eye Centre. OCT images show reflections from interfaces within an object as well as light scattered by microscopic structure so, because papyrus is a layered structure, these images were complex and difficult to interpret. Accordingly, further studies were carried out with a more flexible system at UCL.

It was found that, unless special care was taken to select part of the phantom where the papyrus sheets happened to be thinner than average, the papyrus attenuated the light and, therefore, the OCT signal so significantly that no convincing detail or structure of the papyrus could be seen. This was investigated further by calculating the attenuation coefficient of papyrus at this wavelength which was found to be approximately 17.5/ $\mathrm{mm}$. This is unusually high (compared with $\sim 5 / \mathrm{mm}$ for skin [36]) and suggests that the intensity of light would be reduced by half after about $40 \mu \mathrm{m}$ of papyrus. Equivalently, light passing through a single $300 \mu \mathrm{m}$ thick sheet of papyrus, then reflecting off an interface and returning, would be expected to be reduced in intensity by a factor of 36,000 . At shorter, visible wavelengths, this would be even greater.

Images were generated of the uppermost cross in carbon ink, sliced to show the top surface of the phantom, and of the cross under one sheet of papyrus, sliced to show the level at which the cross would be expected (Fig. 5). The uppermost cross was visible, but the cross under one sheet of papyrus was not, suggesting that the 

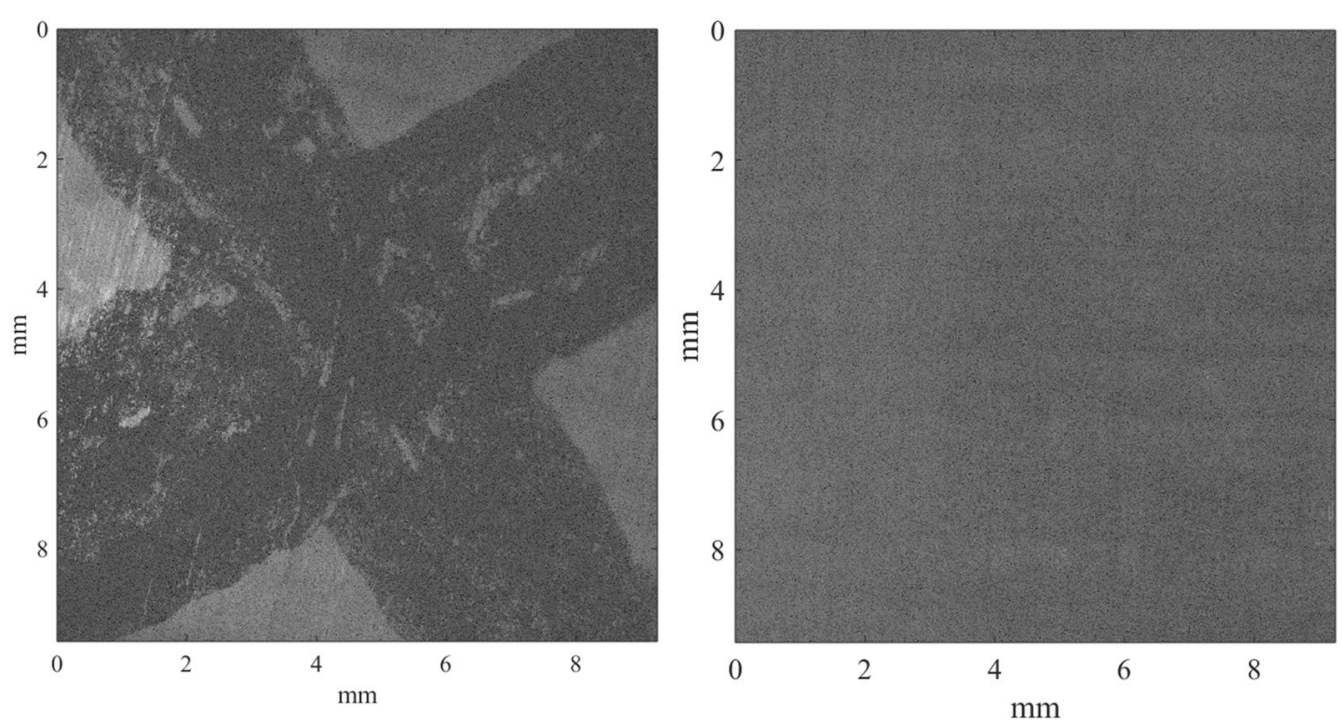

Fig. 5 Showing the uppermost cross in carbon ink just under the surface of the phantom (left) and an image showing the location of the cross under one sheet of papyrus where no ink is visible

attenuation coefficient of papyrus at $1300 \mathrm{~nm}$ is far too high to image below even one sheet of papyrus.

\section{X-ray micro computed tomography}

The top half of all four phantoms, imaged simultaneously, can be seen in a surface rendered XMT image in Fig. 6 with areas of maximum contrast corresponding to the iron-based inks highlighted in red. The physical construction of the phantoms can be seen particularly clearly. Examination of the 3D cross-sectional images showed that the iron ink could be reliably identified, but the carbon ink could not be detected. This suggests that XMT can be used to examine the physical construction of the artefact, and identify heavy metal-based inks, but not carbon-based inks.

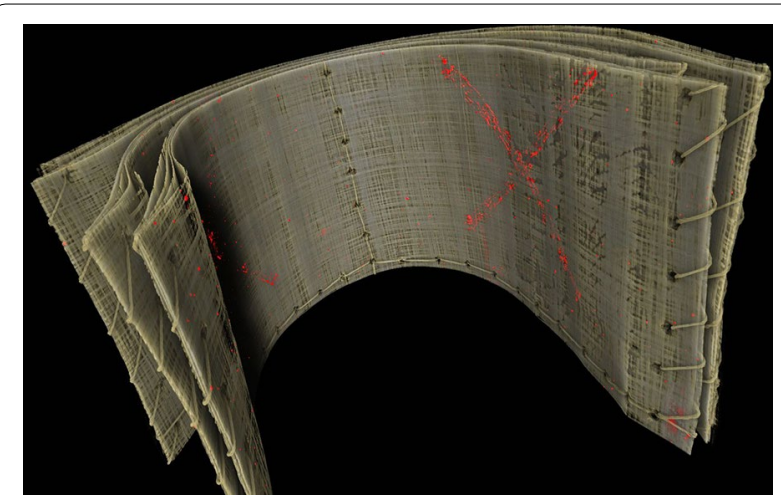

Fig. 6 Surface-rendered X-ray micro computed tomography image showing the top part of all four phantoms, with iron ink highlighted in red

\section{X-ray fluorescence spectroscopy and imaging}

Spectroscopy measurements were taken from parts of the phantom with the pXRF system where no ink was present and compared to those where ink was visible. Two "modes" were available on the system used, which was on loan from UCL Institute of Archaeology: a "soil" mode and an "alloy" mode. The soil mode was calibrated for calcium as well as most other elements which were expected, so this mode was used throughout.

The crosses corresponding to India ink and carbon ink were not detected. Both rely on carbon, which is a light element (atomic number $Z=6$ ) and fluoresces at too low an energy for this system to detect. The lightest element which could be detected was phosphorus $(Z=15)$. The iron present in iron gall ink and red iron ink $(Z=26)$ was readily visible and could be distinguished from background through up to six layers of papyrus (additional layers of plain papyrus were placed above the phantom). Each additional layer of papyrus reduced the intensity of the fluorescence from iron by a factor of approximately 1.7 (Fig. 7).

X-ray fluorescence imaging was carried out at SSRL. The beam was scanned across the phantoms and the emitted fluorescence measured with an energy-resolving detector. The energy region of the $K \alpha$ fluorescence line for each element of interest was identified, and the spatial distribution of the emitted X-ray intensity in this energy band was plotted as an image. Figure 8 shows the images corresponding to iron for the four phantoms. The images of the iron-based inks show all crosses with similar contrast, indicating that the $\mathrm{K} \alpha$ fluorescence of 


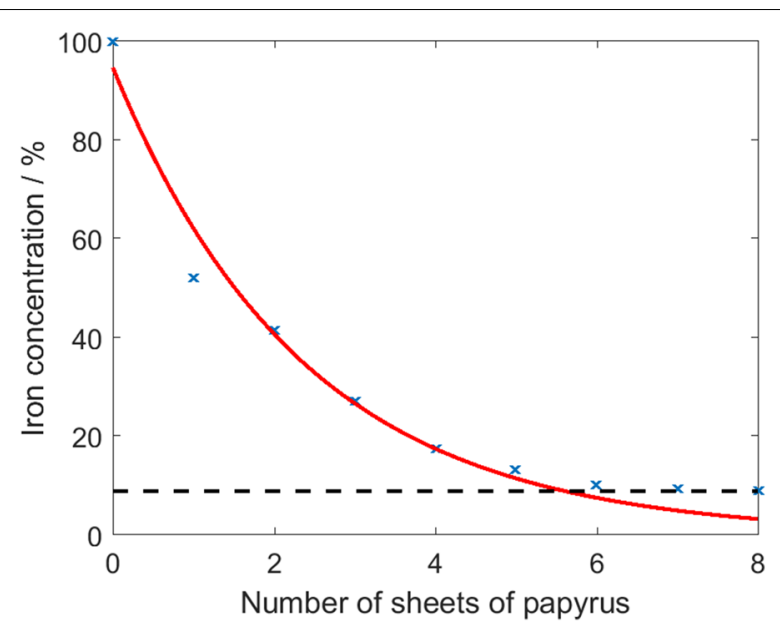

Fig. 7 The concentration of iron as measured by the hand-held pXRF system against the number of sheets of papyrus. The best exponential fit is shown. The dotted line shows background plus two standard deviations above the background and is taken to be the detection limit

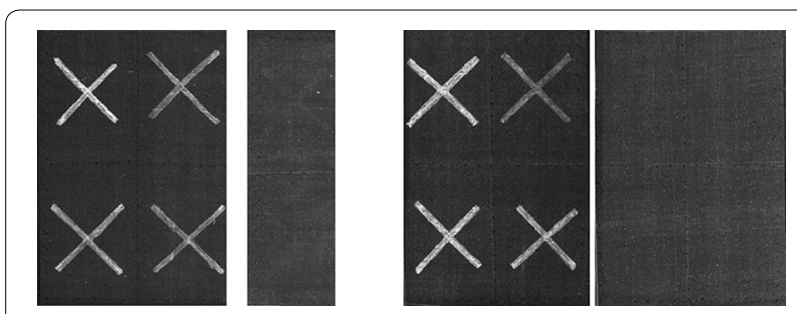

Fig. 8 X-ray fluorescence images showing the presence of iron in the iron-based inks (from left, crosses in: iron gall ink; carbon ink; red iron oxide and India ink). Very faint XRF signals from iron can be seen in the phantoms with carbon based ink. Due to limited time resources, only half of the phantom containing crosses in carbon in was imaged

iron was successfully identified in the ink at all depths. Crosses on the deeper layers were visibly less intense due to attenuation within the phantom. Images of the carbon based ink show little signal corresponding to iron, as expected, although a faint cross can be seen on the top left (only half of the phantom was scanned due to time restrictions).

Carbon Ka fluorescence is low energy $(0.277 \mathrm{keV})$ and so is severely attenuated by absorption in air. The rapid scanning synchrotron system used here was, therefore, unable to resolve carbon in this geometry for several reasons: (1) the low X-ray fluorescence energy of carbon, (2) the detection limit of the detector used, and (3) the fact that the substrate is predominantly carbon. However, images of the carbon ink crosses were able to be resolved by imaging other elements. Weaker signals were seen from $\mathrm{Ca}, \mathrm{Ti}, \mathrm{Mn}, \mathrm{Ni}, \mathrm{Cu}, \mathrm{Zn}, \mathrm{Ga}$ and As due to impurities in the dyes but, surprisingly, there was a very strong signal from bromine in the India ink phantoms. This may be due to an additive in the ink, most likely the cationic surfactant cetyltrimethylammonium bromide $\left(\mathrm{C}_{16} \mathrm{H}_{33}\left(\mathrm{CH}_{3}\right)_{3} \mathrm{~N}^{+} \mathrm{Br}^{-}\right)$[37].

XRF can detect heavy metals through a substantial thickness of papyrus. The pXRF system used here could detect iron-based inks through six sheets of papyrus but a more sensitive synchrotron-based system would be expected to show greater penetration still. The range of specific approaches which are available (from a handheld system to a synchrotron) mean this is a flexible method.

\section{X-ray phase contrast imaging}

Due to time constraints, only the phantoms with crosses in red iron oxide and carbon were examined using $\mathrm{X}$-ray phase contrast imaging. The small field of view $(\sim 2 \mathrm{~cm} \times 5 \mathrm{~cm})$ meant that only selected parts of the phantoms were imaged and images showing part of the red iron oxide cross on the surface of the phantom are shown in Fig. 9a, b. The cross appeared strongest on the absorption image due to the attenuation of the iron in the ink. This image also clearly showed the fibrous structure of the papyrus (Fig. 9a). The cross was also visible in an image of scatter width (Fig. 9b), which was attributed to the refractive index of the ink differing from that of the papyrus. Some faint traces of contrast were seen from the carbon ink, but these were very faint and do not reproduce well.

The laboratory-based X-ray phase contrast system used here was able to detect the iron inks and the structure of the papyrus. Moreover, there was some evidence that the

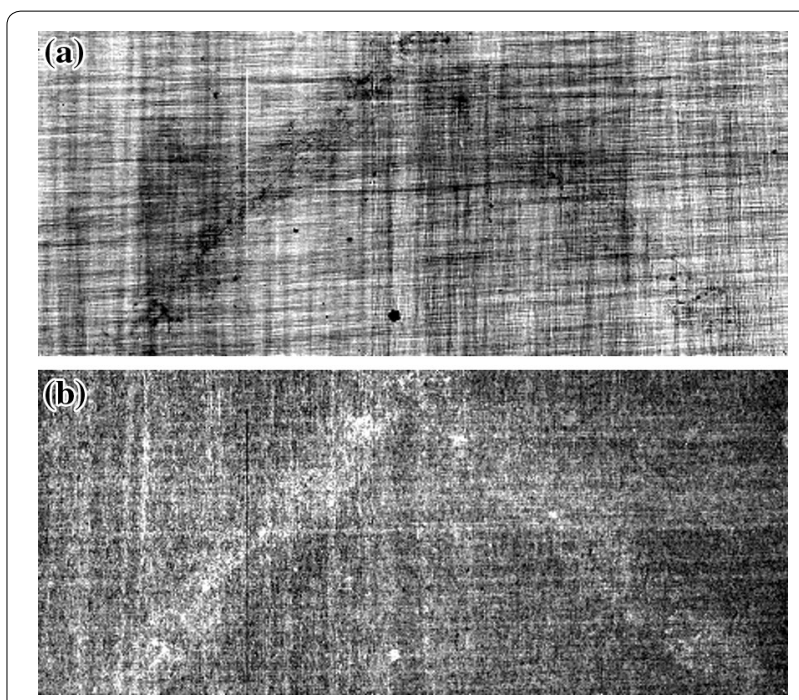

Fig. 9 a X-ray phase contrast absorption image, showing part of the red iron oxide cross on the top layer of papyrus. $\mathbf{b} X$-ray phase contrast image of the same acquisition as $\mathbf{a}$, but processed to show the scatter width 
carbon inks could be seen due to the change in refractive index. However, more assessment is needed to optimise the approach.

\section{Terahertz imaging and spectroscopy}

Figure 10a shows $\mathrm{THz}$ images of the carbon ink at all four depths, demonstrating that ink on all four layers could be detected. A similar result was seen for the India ink cross, though this was less distinct. The iron-based inks were barely visible (Fig. 10b). All four samples were scanned with a spatial resolution of $500 \mu \mathrm{m}$ however, the maximum resolution, which is diffraction-limited, is around $100 \mu \mathrm{m}$. The images shown in Fig. 10b are the peak to peak signal of the reflection from the first layer of each papyrus sample.

$\mathrm{THz}$ was able to penetrate multiple layers and was the only method which appeared to give better contrast for carbon-based inks than for iron-based inks.

\section{Summary of results}

See Table 1.

\section{Discussion}

The different imaging $\rho$ techniques all brought different advantages and disadvantages, so should be seen as complementing each other. Multispectral imaging provides excellent surface detail of both iron- and carbon-based inks with high spatial resolution, but limited penetration. However, this disadvantage is to some extent mitigated by the use of transmission imaging. Optical coherence tomography offered unexpectedly poor penetration due to the high optical attenuation coefficient of papyrus. The $\mathrm{X}$-ray techniques were able to identify iron-based inks even when additional sheets of papyrus were added on top of the phantoms, but were unable to detect carbonbased inks. In particular, XMT provided exquisite images of the internal structure of the material. Furthermore,
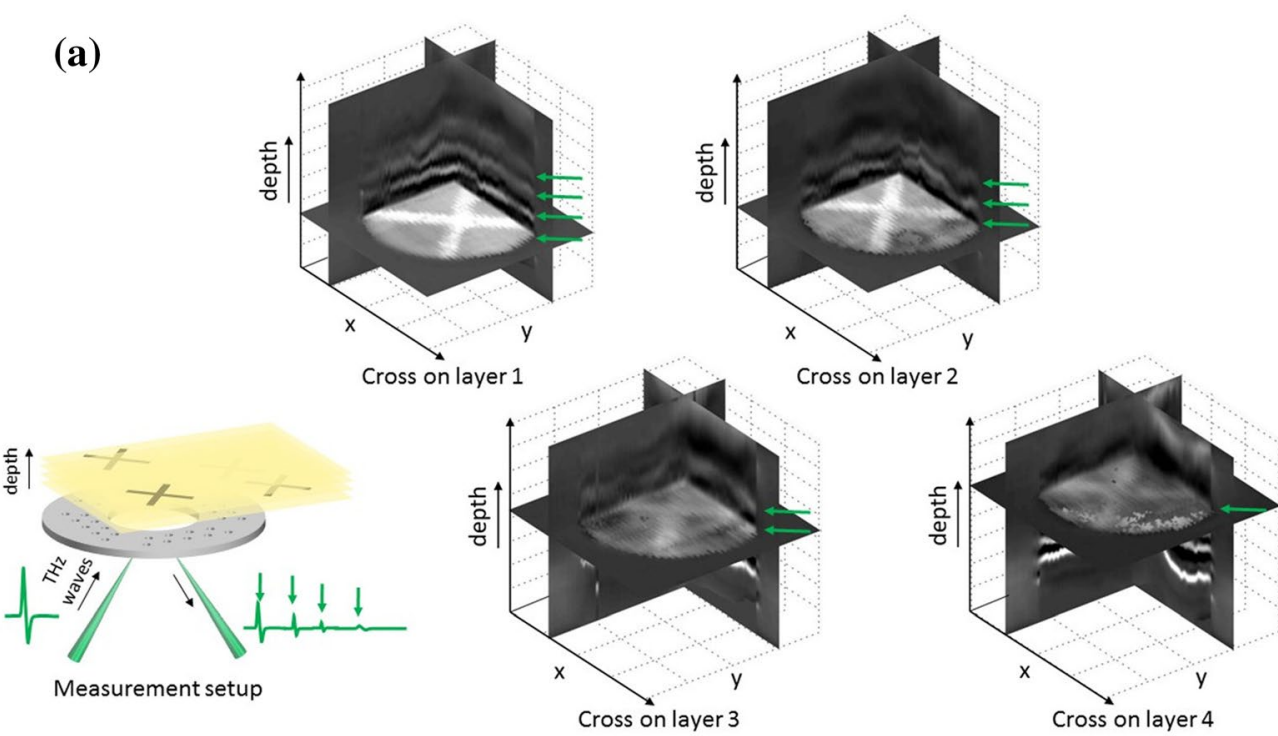

(b)
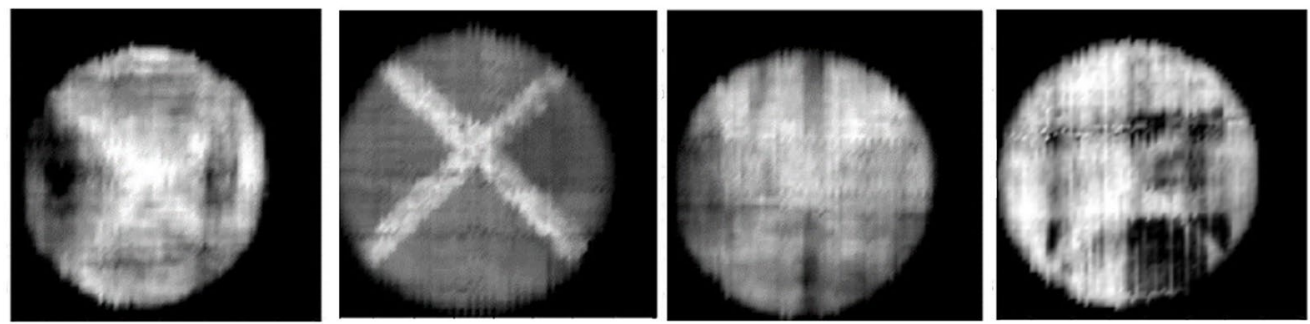

Fig. 10 a The carbon ink crosses imaged at four depths corresponding to each layer using THz imaging. The first layer is on the bottom and gives the strongest contrast; the cross of the fourth layer is still visible but with lower contrast as the THz beam has passed through the preceding three layers and back again before being detected. b THz images of the uppermost cross of made with (from left to right) iron gall ink, carbon ink, red iron oxide, and India ink. This shows that carbon-based inks appear to provide more contrast than metallic-based ink when using THz for imaging 


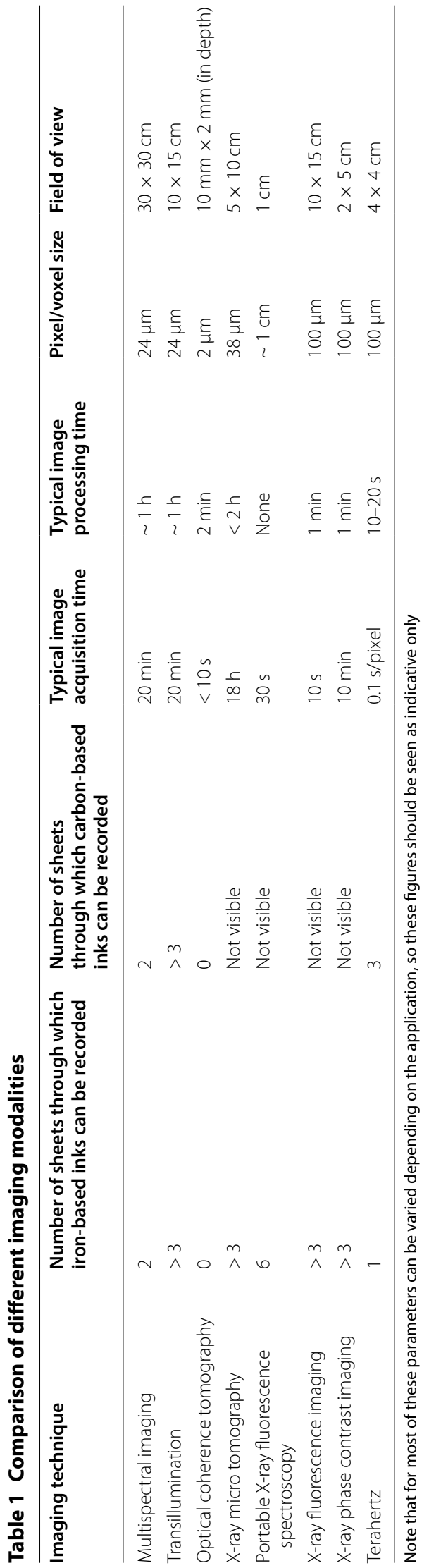


improved performance of X-ray phase contrast imaging would be expected if the system was optimised for this application. In particular, it would be interesting to see whether the scatter width image could show a signal from the carbon-based inks. An pXRF system optimised for the geometry and elements expected in cartonnage is likely to form a convenient and low-cost part of a multimodal approach.

Terahertz imaging was, somewhat to our surprise, more able to detect carbon-based inks than iron-based inks. It is encouraging that $\mathrm{THz}$ appears to be sensitive to inks which are not visible with X-ray techniques. These results are supported by a previous $\mathrm{THz}$ study which was also able to read carbon inks on papyrus [38].

Despite the different modalities being complementary, there are clear applications where certain modalities are likely to be preferred. For example, XMT should be used when the internal structure of cartonnage is required while multispectral imaging is recommended when only surface detail is of interest. However, a full examination of a complex piece of cartonnage is likely to require a multimodal approach, where each technique provides complementary information. This could place a significant barrier in the way of researchers in the cultural heritage sector who might not have access to a wide range of imaging techniques. In addition, given the different geometries and fields of view of the different techniques, a successful multimodal imaging approach will require sophisticated image registration to ensure that features on the different images are spatially aligned.

If an existing instrument which was designed for some other application is repurposed for imaging heritage artefacts, its performance cannot be expected to be optimal. In particular, transillumination, phase contrast X-ray and $\mathrm{THz}$ imaging would be expected to give improved images if the instrumentation, acquisition or processing were optimised.

Finally, the use of simple, predictable, test phantoms has allowed different imaging modalities to be objectively compared. This will inform future studies in which cartonnage will be imaged. It would have been challenging to carry out a speculative study such as this on original material, particularly across multiple institutions on different continents, due to issues involving the transportation of antiquities, including their fragility, and the legal frameworks that (quite rightly) restrict the sharing of these materials across borders.

\section{Conclusion}

No current single imaging technique can identify both iron and carbon-based inks at depths within cartonnage. In order to detect and ultimately read text within cartonnage a multimodal imaging approach is required, but this will, necessarily, be limited by cost, access to imaging systems, and the portability of both the system and the cartonnage. The additional challenges of imaging writing within ancient cartonnage compared to the test phantoms include a more complex geometry, overlying structures such as plaster, adhesives and paint, and the presence of mixtures of inks. It will, therefore, be important to begin by imaging the internal structure with XMT, which will assist with the interpretation of other imaging methods. Ideally, a combination of multispectral imaging techniques would then be employed for surface inks or paints, and X-ray fluorescence imaging for deeper ironbased inks (which would not necessarily require a synchrotron). At the moment, there cannot be confidence that deeper carbon-based inks can be detected, although optimised $\mathrm{THz}$ systems may allow this in future.

An imaging approach based on low-cost and easily accessible methods would be necessary for widespread use in museums and archives. Such an approach might use multispectral imaging and pXRF to identify and clarify text on the surface layers and allow the constituents of inks to be identified. It is noted that there may be barriers to accessing these imaging modalities within the cultural and heritage sector, including associated costs, and building appropriate interdisciplinary networks.

Our work leads us to believe that imaging could be used to identify whether text is present within mummy cartonnage. In some circumstances-for example if ironbased ink is near the surface of cartonnage-imaging may even allow the writing to be read, meaning that it may no longer be necessary to destroy these artefacts in order to read any text inside them. Future work will involve multi-modal imaging on actual mummy cartonnage since the use of phantoms has established that our approach is valid and may yield useful results for historians and related researchers, although issues remain regarding the ability of artefacts to travel to available imaging resources. Our work can also give curators and conservators some confidence that multiple complex imaging methods can be carried out safely without damaging the artefacts. The range of techniques used here will not be commonly available to Egyptologists or papyrologists and indicates that interdisciplinary collaboration is essential to be able to utilise available technologies in the understanding of ancient cultural heritage.

\footnotetext{
Authors' contributions

AG conceived and led the study and wrote the paper. KP designed and made the phantoms and led the multispectral imaging at UCL. MBT and MT were responsible for overall management of the Deep Imaging project ${ }^{4}$ of which this work forms a part. Other authors are listed alphabetically in the author list and made the following contributions: AG, KP, WCB, CJ, MBT and MT carried out multispectral imaging and analysis; UB, PLM and RAW carried out the
}

${ }^{4}$ http://www.ucl.ac.uk/dh/projects/deepimaging. 
rapid-scan XRF imaging at SSRL; GD and DM did the X-ray microCT imaging; SFan, AF and VW did terahertz imaging and analysis; SFarsiu, GL, CMJ and PRTM carried out OCT imaging and analysis; JG, BV and AG did pXRF data collection and analysis; PM, ME and AO carried out phase contrast X-ray imaging and analysis, and RM, KP and AS provided expertise and advice on Egyptology. All authors read and approved the final manuscript.

\section{Author details}

${ }^{1}$ Department of Medical Physics and Biomedical Engineering, UCL, London WC1E 6BT, UK. ${ }^{2}$ Department of Information Studies, UCL, London WC1E 6BT, UK. ${ }^{3}$ SLAC National Accelerator Laboratory, Stanford University, Stanford, CA 94305, USA. ${ }^{4}$ Equipoise Imaging, LLC, Baltimore, MD, USA. ${ }^{5}$ Dental Physical Sciences, Institute of Dentistry, Queen Mary University of London, London E1 4NS, UK. ${ }^{6}$ School of Physics, University of Western Australia, Perth, Australia. ${ }^{7}$ Department of Ophthalmology, Duke University Eye Center, Durham, NC, USA. ${ }^{8}$ Faculty of Engineering Sciences, UCL, London WC1E 6BT, UK. ${ }^{9}$ Department of Geology and Environmental Geosciences, College of Charleston, Charleston, SC, USA. ${ }^{10}$ School of Earth and Environmental Sciences, University of Manchester, Manchester M13 9PL, UK. ${ }^{11}$ Department of Classics and Ancient History, University of Manchester, Manchester M3 3EH, UK.

${ }^{12}$ Petrie Museum of Egyptian Archaeology, UCL, London WC1E 6BT, UK. ${ }^{13}$ R B Toth Associates LLC, Oakton, VA, USA. ${ }^{14}$ College of Arts, Humanities, and Social Sciences, University of Edinburgh, Edinburgh EH8 8JU, UK.

\section{Acknowledgements}

The authors thank Lucy Stagg, Dave Beavan, Daniel Hanlon and James Wilson $(U C L)$ for their help with research data management. We thank Andrew Tindall (UCL) for preparatory work on transillumination imaging, Ruth Siddall and Jo Volley (UCL) for advice on historical inks, pigments and binders and Patrick Quinn (UCL) for the loan of the pXRF system. We also thank the staff of beamline 6-2 at SSRL for help with the rapid-scan XRF imaging and Sanghoon Kim for work on OCT imaging.

\section{Competing interests}

WCB is a principal of Equipoise Imaging, LLC, who provided the LED illumination, capture software, and camera filtering technologies used in this study. The authors declare that they have no competing interests.

\section{Availability of data}

The data is freely available and hosted by UCL as part of the Deep Imaging project (http://www.ucl.ac.uk/dh/projects/deepimaging/data).

\section{Ethics approval and consent to participate}

Not applicable.

\section{Funding}

This work was funded by Arcadia, a charitable fund of Lisbet Rausing and Peter Baldwin as part of the "Deep Imaging Mummy Cases: Non-Destructive Analysis of Multi-Layered Papyrus" project. ${ }^{5}$ Arcadia serves humanity by preserving endangered cultural heritage and ecosystems. Because knowledge should belong to all, Arcadia also promotes open access, seeking to make information available without barriers of cost or distance (see Footnote 5).

BV was funded by an EPSRC/UCL Undergraduate Research Summer Studentship and CJ by the EPSRC SEAHA Centre for Doctoral Training. ME was supported by the Royal Academy of Engineering under the RAEng Research Fellowships scheme. Part of this research was carried out at the Stanford Synchrotron Radiation Lightsource (SSRL), a user facility of the U.S. Department of Energy (DOE), Office of Basic Energy Sciences. PLM thanks STFC for their support (ST/M001814/1).

\section{Publisher's Note}

Springer Nature remains neutral with regard to jurisdictional claims in published maps and institutional affiliations.

Received: 7 October 2017 Accepted: 16 February 2018 Published online: 26 February 2018

\footnotetext{
${ }^{5}$ https://www.arcadiafund.org.uk/about-peter-baldwin-lisbet-rausing/.
}

\section{References}

1. Taylor J, Antoine D. Ancient lives, new discoveries. London: The British Museum; 2014.

2. Adams CV. The manufacture of ancient Egyptian cartonnage cases. Smithson J Hist. 1966;1:55-66.

3. Letronne J-A. Lettre AM. Joseph Passalacqua sur un papyrus Grec, et sur quelques fragmens de plusieurs papyrus appartenant a sa collection d'antiquités Égyptiennes. 1826.

4. Grenfell BP, Hunt AH, Smyly JG. The tebtunis papyri, vol. 1. London: Oxford University Press; 1902.

5. Frösén J. Conservation of ancient papyrus materials. Oxf. Handb. Papyrol. Oxford: Oxford University Press; 2009. p. 87-91. http://www.oxfordhandbooks.com/view/10.1093/oxfordhb/9780199843695.001.0001/oxfordhb9780199843695-e-004. Accessed 28 Sept 2017.

6. Mazza R. New testament papyri from mummy cartonnage: accounts don't balance. facesandvoices.wordpress.com/. 2014. https://facesandvoices.wordpress.com/2014/05/13/new-testament-papyri-from-mummycartonnage-accounts-dont-balance/.

7. Mazza R. Another Indiana Jones? Josh McDowell, mummy cartonnage and biblical papyri. Faces Voices. 2014. https://facesandvoices.wordpress. com/2014/05/05/another-indiana-jones-josh-mcdowell-mummy-cartonnage-and-biblical-papyri/. Accessed 13 July 2017.

8. Jones B. The "First Century" Gospel of Mark, Josh McDowell, and Mummy Masks: What They All Have in Common. http://www.bricecjones.com/1/ post/2014/05/the-first-century-gospel-of-mark-josh-mcdowell-andmummy-masks-what-they-all-have-in-common.html. Accessed 3 July 2017.

9. Ehrman B. New manuscripts and the destruction of antiquities. https:// ehrmanblog.org/new-manuscripts-and-the-destruction-of-antiquities/. Accessed 3 July 2017.

10. Barford P. US Christian Apologist Fanatics Destroy Ancient Artefacts Portable Antiq. Collect. Herit. Issues. http://paul-barford.blogspot. com/2014/05/us-christian-apologist-fanatics-destroy.html. Accessed 3 July 2017.

11. Scott DA. A review of ancient Egyptian pigments and cosmetics. Stud Conserv. 2016;61:185-202.

12. Pogue BW, Patterson MS. Review of tissue simulating phantoms for optical spectroscopy, imaging and dosimetry. J Biomed Opt. 2006;11:041102.

13. Xu XG. An exponential growth of computational phantom research in radiation protection, imaging, and radiotherapy: a review of the fifty-year history. Phys Med Biol. 2014;59:R233.

14. Heginbotham A, Bassett J, Bourgarit D, Eveleigh C, Glinsman L, Hook D, et al. The copper CHARM set: a new set of certified reference materials for the standardization of quantitative $X$-ray fluorescence analysis of heritage copper alloys. Archaeometry. 2015;57:856-68.

15. Giacometti A, Campagnolo A, MacDonald L, Mahony S, Robson S, Weyrich $T$, et al. The value of critical destruction: evaluating multispectral image processing methods for the analysis of primary historical texts. Digit Scholarsh Humanit. 2017;32:101-22.

16. Easton RL, Knox KT, Christens-Barry WA. Multispectral imaging of the Archimedes palimpsest. Appl. Imag. Pattern Recognit. In: Workshop 2003 Proc. 32nd. IEEE; 2003. p. 111-6. http://ieeexplore.ieee.org/abstract/document/1284258/. Accessed 25 Apr 2017.

17. Fischer C, Kakoulli I. Multispectral and hyperspectral imaging technologies in conservation: current research and potential applications. Stud Conserv. 2006;51:3-16.

18. France FG. Advanced spectral imaging for noninvasive microanalysis of cultural heritage materials: review of application to documents in the U.S. library of congress. Appl Spectrosc. 2011;65:565-74.

19. Boyle RD, Hiary H. Watermark location via back-lighting and recto removal. Int J Doc Anal Recognit. 2009;12:33-46.

20. Huang D, Swanson EA, Lin CP, Schuman JS, Stinson WG, Chang W, et al. Optical coherence tomography. Science. 1991;254:1178-81.

21. Adler DC, Stenger J, Gorczynska I, Lie H, Hensick T, Spronk R, et al. Comparison of three-dimensional optical coherence tomography and high resolution photography for art conservation studies. Opt Express. 2007;15:15972-86.

22. Targowski P, Iwanicka M. Optical coherence tomography: its role in the non-invasive structural examination and conservation of cultural heritage objects-a review. Appl Phys A. 2012;106:265-77. 
23. Liang H, Mari M, Cheung CS, Kogou S, Johnson P, Filippidis G. Optical coherence tomography and non-linear microscopy for paintings-a study of the complementary capabilities and laser degradation effects. Opt Express. 2017;25:19640-53.

24. Mills D, Davis GR, Lai Y kun, Rosin P. Apocalypto: revealing lost text with XMT. SPIE Opt. Eng. Appl. International Society for Optics and Photonics; 2014. p. 921210.

25. Davis GR, Mills D. Brute force absorption contrast microtomography. In: Stock SR, editor. 2014. p. 92120l. http://proceedings.spiedigitallibrary.org/ proceeding.aspx?doi=10.1117/12.2061929. Accessed 28 Sept 2017.

26. Favero PA, Mass J, Delaney JK, Woll AR, Hull AM, Dooley KA, et al. Reflectance imaging spectroscopy and synchrotron radiation X-ray fluorescence mapping used in a technical study of The Blue Room by Pablo Picasso. Herit Sci. 2017:5:13

27. Manso M, Costa M, Carvalho ML. From papyrus to paper: elemental characterization by X-ray fluorescence spectrometry. Nucl Instrum Methods Phys Res Sect Accel Spectrom Detect Assoc Equip. 2007;580:732-4.

28. Bergmann U, Manning PL, Wogelius RA. Chemical mapping of paleontological and archeological artifacts with synchrotron X-rays. Annu Rev Anal Chem. 2012;5:361-89.

29. Bukreeva I, Mittone A, Bravin A, Festa G, Alessandrelli M, Coan P, et al. Virtual unrolling and deciphering of Herculaneum papyri by X-ray phasecontrast tomography. Sci Rep. 2016;6:27227.

30. Mocella V, Brun E, Ferrero C, Delattre D. Revealing letters in rolled Herculaneum papyri by X-ray phase-contrast imaging. Nat Commun. 2015;6:5895.
31. Olivo A, Speller R. A coded-aperture technique allowing X-ray phase contrast imaging with conventional sources. Appl Phys Lett. 2007;91:074106.

32. Modregger P, Cremona TP, Benarafa C, Schittny JC, Olivo A, Endrizzi M. Small angle X-ray scattering with edge-illumination. Sci Rep. 2016;6:30940

33. Endrizzi M, Diemoz PC, Millard TP, Louise Jones J, Speller RD, Robinson IK, et al. Hard X-ray dark-field imaging with incoherent sample illumination. Appl Phys Lett. 2014;104:024106.

34. Bardon T, May RK, Taday PF, Strlic M. Material characterization of historical parchment using terahertz time-domain spectroscopy. In: Proc. 2014 39th Int. Conf. Infrared Millim. Terahertz Waves IRMMW-THz Tucson AZ USA. 2014. p. 14-9.

35. Jackson JB, Bowen J, Walker G, Labaune J, Mourou G, Menu M, et al. A survey of terahertz applications in cultural heritage conservation science. IEEE Trans Terahertz Sci Technol. 2011;1:220-31.

36. Jacques SL. Optical properties of biological tissues: a review. Phys Med Biol. 2013;58:R37.

37. Mohamed GG, Ali TA, El-Shahat MF, Al-Sabagh AM, Migahed MA. New screen-printed ion-selective electrodes for potentiometric titration of cetyltrimethylammonium bromide in different civilic media. Electroanalysis. 2010;22:2587-99.

38. Labaune J, Jackson JB, Pagès-Camagna S, Duling IN, Menu M, Mourou GA Papyrus imaging with terahertz time domain spectroscopy. Appl Phys A. 2010;100:607-12.

\section{Submit your manuscript to a SpringerOpen ${ }^{\circ}$ journal and benefit from:}

- Convenient online submission

$\checkmark$ Rigorous peer review

- Open access: articles freely available online

- High visibility within the field

- Retaining the copyright to your article

Submit your next manuscript at $\gg$ springeropen.com 